\title{
Applications of a simultaneous differential scanning calorimetry-thermomicroscopy system
}

\author{
Gage P. Ashton ${ }^{1}\left[\right.$. Edward L. Charsley ${ }^{1} \cdot$ Lindsay P. Harding $^{1}\left(\mathbb{D} \cdot\right.$ Gareth M. B. Parkes $^{1}(\mathbb{C}$
}

Received: 26 March 2020 / Accepted: 20 December 2020 / Published online: 5 February 2021

(c) The Author(s) 2021

\begin{abstract}
A simultaneous DSC-thermomicroscopy system (DSC450 Linkam Scientific) was applied to the study of phase transitions in rubidium nitrate and silver iodide, the oxidation of polyethylene, the thermal degradation of polylactic acid and magnesium nitrate hexahydrate, and the reversible transitions in thermochromic inks. The results demonstrated the benefits of obtaining simultaneous optical data, both images and light intensity measurements, with DSC, particularly in the interpretation of complex processes and the detection of events with small changes in enthalpy.
\end{abstract}

Keywords Thermomicroscopy $\cdot$ DSC $\cdot$ Thermochromic $\cdot 3$ D printer filament $\cdot$ Hot-stage microscopy

\section{List of symbols}

3D

Three-dimensional

DSC Differential scanning calorimetry

DSC-TM Simultaneous differential scanning calorimetry-thermomicroscopy

FDM Fused deposition modelling

OIT Oxidative induction time

PLA Polylactic acid

RLI Reflected light intensity

ROI Region of interest

STA Simultaneous thermal analysis

$T_{\mathrm{g}} \quad$ Glass transition temperature

TG-DSC Thermogravimetry-differential scanning calorimetry

$T_{\mathrm{m}} \quad$ Melting temperature

TM Thermomicroscopy

$T_{\text {onset }} \quad$ Onset temperature (measured to $\pm 0.1^{\circ} \mathrm{C}$ )

UHMWPE Ultrahigh molecular weight polyethylene
Gage P. Ashton

G.P.Ashton@hud.ac.uk

1 Thermal Methods Research Unit, School of Applied Sciences, University of Huddersfield, Huddersfield HD1 3DH, UK

\section{Introduction}

It is now generally recognised that more than one thermal analysis technique is required for a detailed interpretation of the reactions taking place in a given system. In order to eliminate the uncertainly inherent in the comparison of the results obtained using two or more individual thermal analysis units, it is advantageous to carry them out simultaneously, that is, on the same sample at the same time [1].

DSC is by far the most widely used and versatile thermal analysis technique since it can, in theory, detect any reaction which takes place with a change in energy. However, it is non-specific in nature and hence, to take a simple example, cannot distinguish between a phase change and a fusion reaction. This is readily accomplished by the technique of thermomicroscopy which enables the direct observation of phenomena such as solid-solid transitions, fusion and decomposition and also processes such sintering, decrepitation, creeping of a liquid melt and foaming reactions which can complicate the interpretation of a DSC curve. Simultaneous DSC-thermomicroscopy systems have been developed by incorporating microscopes into both power compensated [2,3] and heat flux DSCs [4]. In an alternative approach, DSC sensors have also been introduced into microscopy hot stages $[5,6]$.

In the present work, we have used a recently introduced simultaneous DSC-thermomicroscopy system which incorporates a heat flux DSC plate into a hot stage operating over the range -150 to $450{ }^{\circ} \mathrm{C}$. The system has been applied to study a wide range of materials with a view to investigate 
the benefits of carrying out DSC and thermomicroscopy simultaneously.

\section{Materials and methods}

\section{Instrumentation}

Figure 1 shows a photograph of the optical DSC450 system used in this study. It comprises a DSC450 (described below) interfaced to a T96 controller unit (Linkam Scientific). Active cooling is provided by a LNP96 pumping unit connected to a liquid nitrogen reservoir with exhaust gas being used to sweep the DSC window to minimise the build-up of condensates. Imaging is obtained through a high-resolution digital camera (FLIR) coupled to a stereoscopic microscope (SD6, Leica) equipped with a trinocular head. The system is controlled using the LINK software (v1.2.5.13, Linkam) running under Windows 10 (Microsoft).

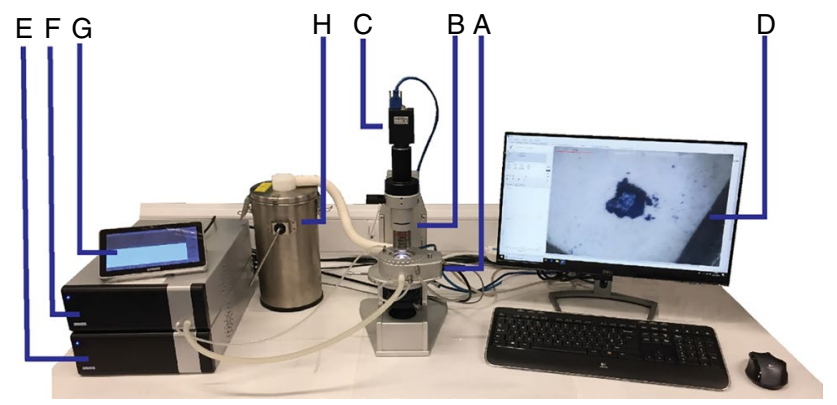

Fig. 1 A labelled photograph of the equipment used for this study. a Optical DSC450, b Linkam imaging station (a stereoscopic microscope), $\mathbf{c}$ high-resolution digital camera, $\mathbf{d}$ PC running LINK, e controller unit, $\mathbf{f}$ liquid nitrogen pumping unit, $\mathbf{g}$ touchscreen control and $\mathbf{h}$ liquid nitrogen reservoir

\section{The DSC450}

A cross section of the DSC450 is shown in Scheme 1. It comprises a water-cooled body encasing a silver heating block upon which a chromel heat flux plate is situated. Temperature measurement of the heating block is provided using a Pt100 resistor, while DSC measurement is achieved using constantan thermocouples. The DSC450 can operate between -150 and $450{ }^{\circ} \mathrm{C}$ with cooling achieved using liquid nitrogen pumped from a reservoir (LN2). Figure 2 shows the temperature control achievable with the unit for both heating (A) and cooling (B).

Gas inlet and outlet ports allow for control of the atmosphere. A window situated immediately above the DSC plate is made from sapphire to provide good heat conduction. An outer silica window gives a gas-tight seal for controlled atmosphere studies.

\section{Imaging}

For this work, the DSC450 was used in combination with two interchangeable microscopes. The first utilised a Linkam imaging station, a monocular microscope with changeable objective lens. Illumination for the imaging station was operated in dark field mode with light originating from a series of inbuilt white LEDs. The second microscope (SD6, Leica) incorporated a trinocular head, and sample illumination utilised a Leica L2 light source. Both microscopes used a 12 MP digital camera (FLIR) interfaced directly to the PC to record images.

\section{Software}

DSC and optical data were simultaneously collected using the LINK software (v1.2.5.13, Linkam). The software

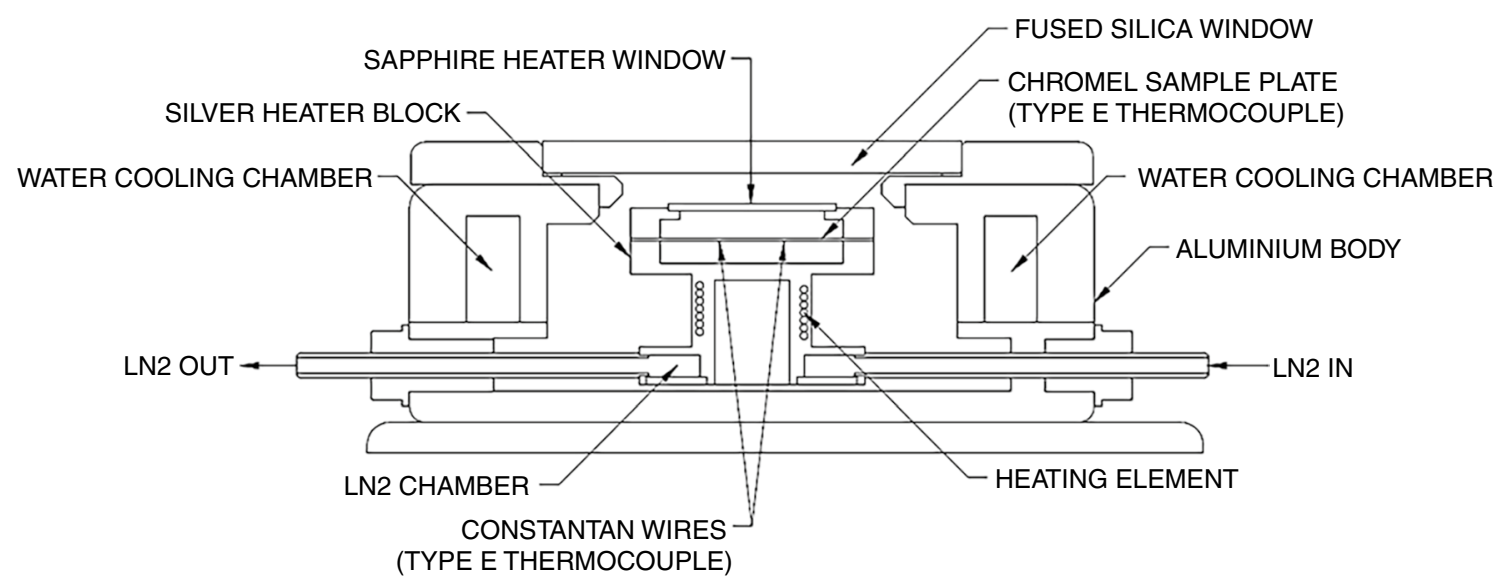

Scheme 1 A labelled cross-sectional line drawing of the Optical DSC450 
Fig. 2 Isothermal stepping experiments using the Optical DSC450. a Heating in $25^{\circ} \mathrm{C}$ increments with 5-min isothermal periods, $\mathbf{b}$ cooling in $25{ }^{\circ} \mathrm{C}$ decrements with 5 -min isothermal periods

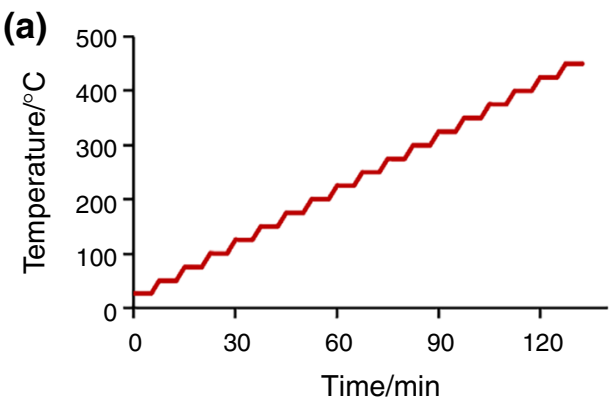

provides a real-time display of temperature, DSC and images. Additionally, the software provides a measure of the reflected light intensity (RLI) of part of the sample using a 'region of interest' (ROI) feature.

\section{Experimental}

\section{General}

Aluminium pans (5 mm (d), $3 \mathrm{~mm}(\mathrm{~h})$, Linkam) were used throughout this study. An empty pan of the same specifications was used as reference. Crystalline or powdered samples were lightly compressed into the sample pan using the provided tamping tool to ensure a good thermal contact with the pan and a flat sample surface for optimum microscopy.

The majority of experiments were performed under an inert atmosphere of nitrogen flowing at $50 \mathrm{~mL} \mathrm{~min}^{-1}$ set by a mass flow controller (0154, Brooks instruments) with the exception of the oxidative induction time experiment (using air) described later.

The magnification was set to $\times 16$ to ensure that the sample pan covered the full field of view. A constant level of illumination was used for all experiments. The software was configured to collect micrographs at a rate of once every $10 \mathrm{~s}$ with auto-brightening and white balance enabled.

After acquisition, DSC data were exported into Excel and corrected by subtracting the natural baseline obtained using two empty pans.

\section{Calibration}

Temperature calibration was performed using certified melting point standards obtained from LGC Limited (LGC2601 indium $T_{\mathrm{m}}=156.6{ }^{\circ} \mathrm{C}, \mathrm{LGC} 2609$ tin $T_{\mathrm{m}}=231.9^{\circ} \mathrm{C}$ and LGC2611 zinc $T_{\mathrm{m}}=419.5^{\circ} \mathrm{C}$ ).

Temperature calibration experiments were performed at a heating rate of $10{ }^{\circ} \mathrm{C} \mathrm{min}{ }^{-1}$ from room temperature to $20^{\circ} \mathrm{C}$ beyond each transition temperature, ensuring the DSC response returned to a stable baseline.

\section{Oxidative induction time (OIT) of polyethylene}

Ultrahigh molecular weight polyethylene (UHMWPE, Goodfellow) was prepared using a metal hole punch to give discs of dimensions of $1.0 \mathrm{~mm}$ high and $4.1 \mathrm{~mm}$ in diameter. These dimensions equated to a mass of ca. $13 \mathrm{mg}$.

A temperature programme of $30-205^{\circ} \mathrm{C}$ at $10{ }^{\circ} \mathrm{C} \mathrm{min}^{-1}$ was used with the final temperature being held until the end of the experiment.

The OIT effect was analysed initially under an inert nitrogen atmosphere $\left(50 \mathrm{~mL} \mathrm{~min}^{-1}\right)$, and $337 \mathrm{~s}$ into the isothermal period, the atmosphere was switched to dry air using the same flow rate.

\section{Polymorphic transitions of rubidium nitrate}

Crystals of rubidium nitrate (Acros, 99.8\%, $9.64 \mathrm{mg}$ ) were analysed using a temperature programme of $30-400{ }^{\circ} \mathrm{C}$ at $10{ }^{\circ} \mathrm{C} \mathrm{min}{ }^{-1}$. Prior to analysis, the crystals were melted at $320{ }^{\circ} \mathrm{C}$ to provide a smooth surface on resolidification.

\section{Solid-solid transition of silver iodide}

Silver iodide powder (Aldrich, 99\%, $10.02 \mathrm{mg}$ ) was analysed by heating from 30 to $180{ }^{\circ} \mathrm{C}$ at a rate of $10{ }^{\circ} \mathrm{C} \mathrm{min}^{-1}$ with a 2-min isothermal period at $180^{\circ} \mathrm{C}$. The sample was then cooled at $-10{ }^{\circ} \mathrm{C} \mathrm{min}{ }^{-1}$ from 180 to $30{ }^{\circ} \mathrm{C}$.

\section{Reversible colour change of a thermochromic ink}

Thermochromic FriXion ink (FriXion 0.7 blue ball pen ink, $11.78 \mathrm{mg}$ ) was dried and analysed directly in a pan. A comparative study was made using higher magnification of a single 'dot' of ink on paper (with negligible mass). Both experiments followed a heating programme of $0-75^{\circ} \mathrm{C}$ with a 2-min isothermal period before cooling down to $-40^{\circ} \mathrm{C}$, and heating rates were set at $\pm 10{ }^{\circ} \mathrm{C} \mathrm{min}^{-1}$.

\section{Thermal transitions of a 3D printer filament}

A sample of polylactic acid (PLA) 3D printer filament (Zortrax PLApro, $h=0.2 \mathrm{~mm}, 4.45 \mathrm{mg}$ ) was cut from the bulk 
material and placed within the sample pan. The sample was then heated from 30 to $400{ }^{\circ} \mathrm{C}$ at a rate of $10{ }^{\circ} \mathrm{C} \mathrm{min}-1$.

\section{Thermal degradation of magnesium nitrate hexahydrate}

Magnesium nitrate hexahydrate (Acros, $99.9+\%, 2.5 \mathrm{mg}$ ) was analysed using a temperature programme of $10{ }^{\circ} \mathrm{C} \mathrm{min}-1$ from 30 to $450{ }^{\circ} \mathrm{C}$.

\section{Results and discussion}

\section{Oxidative induction time (OIT) of polyethylene}

One advantage of reflected light thermomicroscopy systems using DSC type open pans is good atmosphere control which is difficult to achieve when samples are placed between microscopy cover glasses. This enables the interaction of solids with reactive gases to be readily studied, and this is illustrated below by the oxidative degradation of polyethylene.

Polymeric materials are often heated above their melting points during manufacturing to enable the polymer to flow more easily [7]. However, many polymers undergo degradation shortly after melting, a clearly undesirable feature in the manufacturing process [8]. The oxidative induction time (OIT) test is widely used by the oil and polymer industries to evaluate the stability of a material at elevated temperatures under different atmospheres [9]. Typically, a sample is heated above its melting point and held at an isothermal temperature under an inert atmosphere. During the isothermal period, the sample is exposed to an oxidative atmosphere and the time taken until the onset of oxidative degradation is measured [10]. The OIT may also be used to evaluate the performance of thermal stabilising compounds in materials, achieved by comparing the amount of stabiliser added to the increase in OIT at a given temperature [11].
Figure 3 shows the results of the OIT for a sample of UHMWPE. The melting of the polymer was observed at $T_{\text {onset }} 109.9^{\circ} \mathrm{C}$, and no further events are observed until $205{ }^{\circ} \mathrm{C}$. The DSC profile remains unchanged during the isothermal period while under the inert nitrogen atmosphere. During the isothermal period, the atmosphere was then switched to air (vertical dashed line). The onset of the exothermic oxidation was observed after $7 \mathrm{~min}$ and $52 \mathrm{~s}$ into the isothermal period equating to an OIT of $2 \mathrm{~min}$ and $15 \mathrm{~s}$ for UHMWPE under these conditions.

These processes can also be observed optically. A comparison between micrograph $t_{0}$ and micrograph A shows the change from an opaque disc to a transparent liquid as the polymer melts. Micrographs B and C show how the surface texture of the liquid polymer is influenced by the change in atmosphere as oxidative degradation begins.

\section{Polymorphic transitions of rubidium nitrate}

Materials showing multiple polymorphic transitions are potentially attractive temperature calibration standards since they enable a wide temperature range to be covered by a single material. Thus, the ICTAC Standardisation Committee suggested rubidium nitrate as a possible temperature calibration standard since it has three clearly distinct solid-state transitions over the range $150-280{ }^{\circ} \mathrm{C}$, followed by fusion around $310^{\circ} \mathrm{C}$ [12].

Figure 4 shows the results for the analysis of a sample of rubidium nitrate (previously pre-melted and resolidified) heated at $10{ }^{\circ} \mathrm{C} \mathrm{min}^{-1}$. The DSC profile shows three peaks corresponding to the solid-solid transitions $\left(T_{\text {onsets }} 163.9^{\circ} \mathrm{C}\right.$, $228.2^{\circ} \mathrm{C}$ and $279.0{ }^{\circ} \mathrm{C}$ ) with the final peak at $306.2^{\circ} \mathrm{C}$ corresponding to the sample melting. The corresponding ROI profile, based on the reflected light, reveals the same transitions as a series of steps caused by changes in the reflectivity of the sample. These values are in general agreement with those previously reported in the literature [13].

The melting can be seen particularly clearly from micrographs A and B. The solid-solid transitions were subtle to
Fig. 3 Oxidative induction test being performed on a sample of ultrahigh molecular weight polyethylene (UHMWPE). The DSC profile (blue solid line) and temperature programme (red dashed line) have been plotted as a function of time. The vertical line indicates when the gas is switched from $\mathrm{N}_{2}$ to air. Selected micrographs (labelled $t_{0}$ and $\mathbf{a}-\mathbf{c}$ ) link to the DSC profile. (Color figure online)

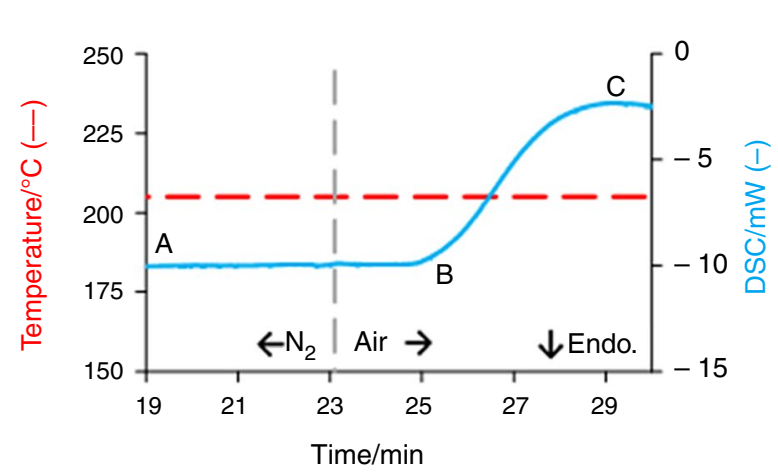

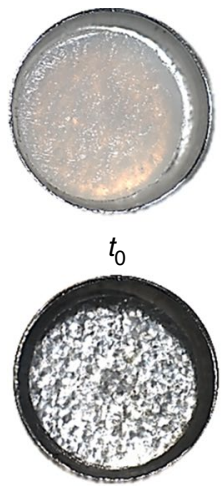

(b) $25.5 \mathrm{~min}$

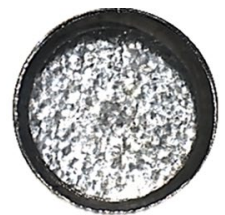

(a) $19.0 \mathrm{~min}$

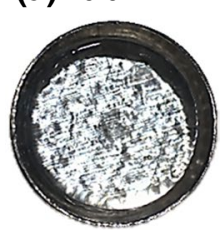

(c) $29.0 \mathrm{~min}$ 
Fig. 4 Analysis of rubidium nitrate using the DSC450. DSC (lower) and ROI intensity (upper) profiles are plotted as a function of temperature. Selected micrographs (labelled a, b) link to the DSC and ROI profiles

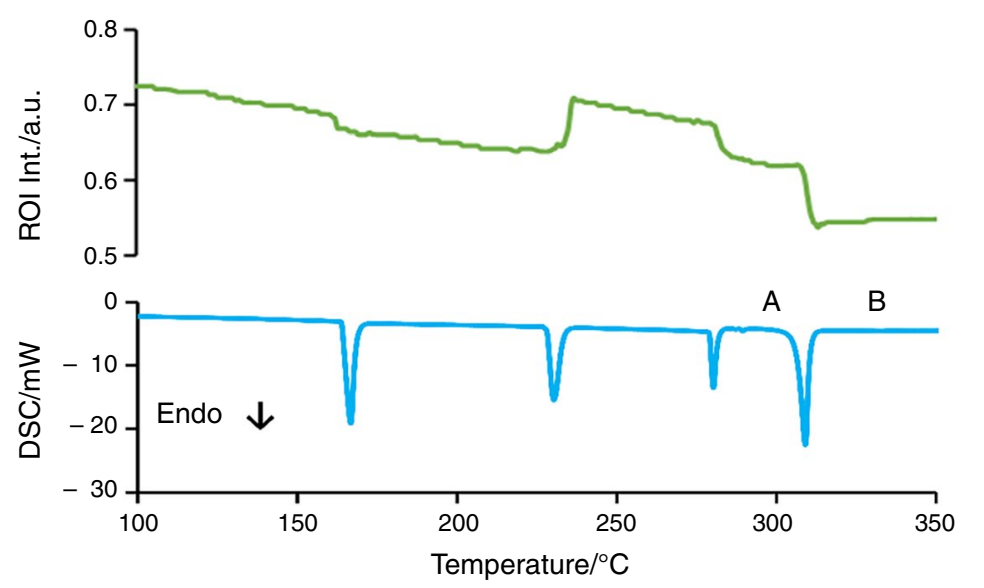

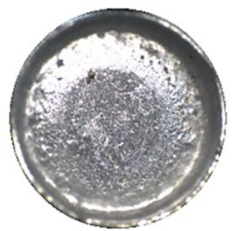

(a) $330^{\circ} \mathrm{C}$

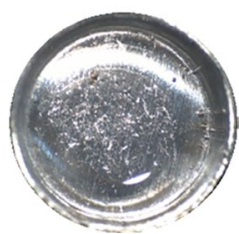

(b) $330^{\circ} \mathrm{C}$ the human eye when comparing micrographs; however, they are clearly apparent from the additional ROI data.

\section{Solid-solid transition of silver iodide}

The solid-solid transition in silver iodide has been widely studied because it undergoes a transition from the $\beta$ form to the fast ion conducting $\alpha$ form at $147^{\circ} \mathrm{C}$ [14]. This is a property of particular interest to materials engineers [15], as fast ion conductors have conductivities similar to those of aqueous solutions of strong electrolytes or molten salts [16].

The solid-solid transition of silver iodide has been studied using non-conventional heating techniques based on high-frequency microwave heating. Binner et al. [17] have used silver iodide to show how microwave energy can lower the transition temperature through 'the microwave effect'. This effect was also demonstrated using a novel in situ microwave-heated PXRD method [18].

Figure 5 shows the result obtained for a sample of silver iodide heated and then cooled at $10{ }^{\circ} \mathrm{C} \mathrm{min}^{-1}$. The DSC profile shows the transition from the $\beta$ form to the higher conductive $\alpha$ form at $148.2{ }^{\circ} \mathrm{C}$. The reverse transition on cooling was at a lower temperature of $140.2{ }^{\circ} \mathrm{C}$. The transitions are reflected in the associated micrographs (A-D) with a clear distinction between the pale beige $\beta$ form and the golden yellow $\alpha$ form. This colour change is also accompanied by a small expansion and contraction.

\section{Reversible colour change of a thermochromic ink}

In 2006, the Pilot Pen Ink Company, Japan, introduced a new type of erasable pen, called the FriXion pen [19]. In this pen, the ink is erased by the heat caused by friction between the hard, smooth plastic "eraser" on the top of the pen and the paper containing the ink. The heat generated causes the thermochromic ink to turn colourless when a temperature of $60{ }^{\circ} \mathrm{C}$ is reached. The change is reversible and the ink turns back to its original colour when cooled below $-10{ }^{\circ} \mathrm{C}$.

The composition of these thermochromic inks is based on three key components: a dye acting as an electron acceptor, a weak acid and a thermoregulatory compound [20]. This combination of components allows a tuneable colour transition to be achieved at a given temperature (that of the frictional heat generated during erasing) through a reversible colour changing acid-base reaction [21].

The results of two separate experiments using thermochromic ink (FriXion, Pilot pens) are shown in Fig. 6i, ii.
Fig. 5 Analysis of silver iodide using the DSC450. The DSC profile has been plotted as a function of temperature. Selected micrographs (labelled a-d link to the DSC

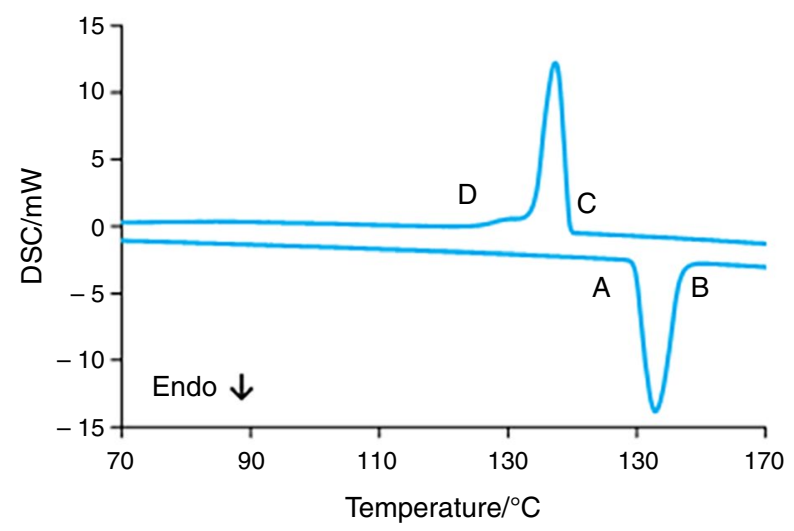

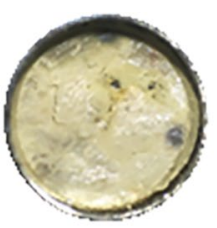

(a) $145^{\circ} \mathrm{C}$

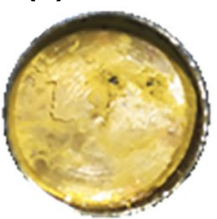

(c) $140^{\circ} \mathrm{C}$

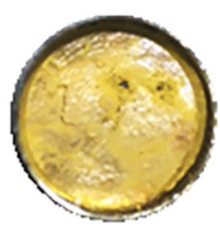

(b) $160^{\circ} \mathrm{C}$

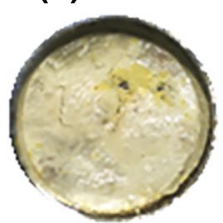

(d) $125^{\circ} \mathrm{C}$ 
Fig. 6 Analysis of FriXion ink using the DSC450. i DSC profile of large mass of dried FriXion ink plotted as a function of temperature. ii ROI profile of ink on paper plotted as a function of temperature. Selected micrographs (labelled a-d, link to the ROI profile (ii). The micrographs represent an area of $1 \mathrm{~mm}^{2}$
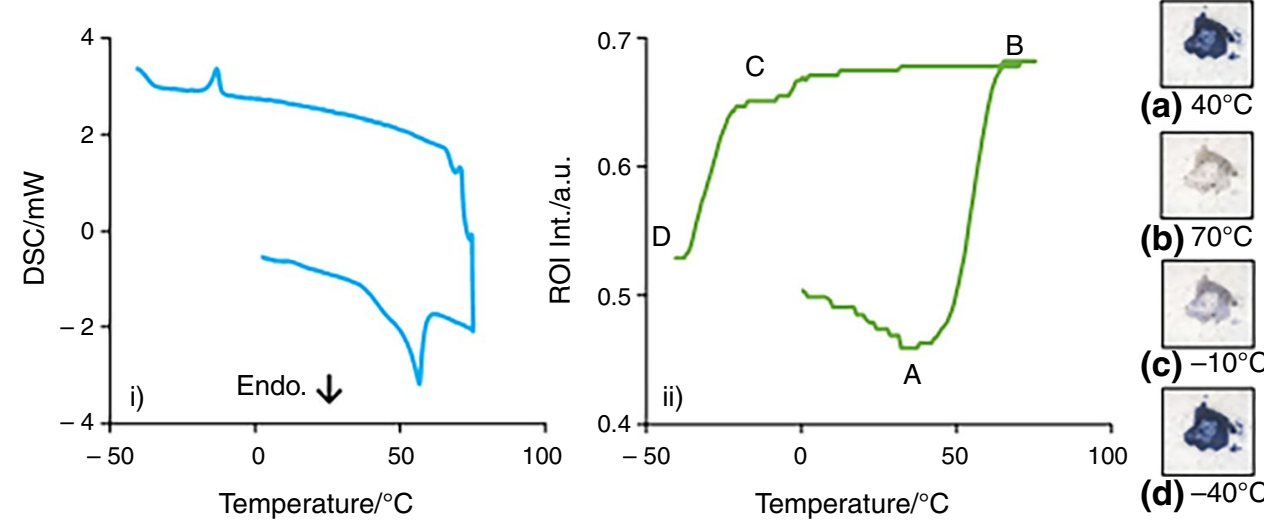

(a) $40^{\circ} \mathrm{C}$

(b) $70^{\circ} \mathrm{C}$

(c) $-10^{\circ} \mathrm{C}$

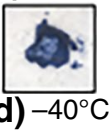

Figure 6i shows the results from the analysis of a sample of ink that was added to and dried directly into a DSC pan. Upon heating from 0 to $75^{\circ} \mathrm{C}$, a broad endotherm $\left(T_{\text {onset }}=38.7^{\circ} \mathrm{C}\right)$ is observed as the ink undergoes a transition. The sample is then held at $75{ }^{\circ} \mathrm{C}$ before cooling to $-40^{\circ} \mathrm{C}$. An exothermic peak is seen $\left(T_{\text {onset }}=-11.2^{\circ} \mathrm{C}\right)$ as the ink colour begins to return.

Figure 6ii shows the ROI analysis of a single dot of FriXion ink accompanied with micrographs A to D. The ROI profile and selected micrographs were obtained in an experiment where a dot of blue FriXion ink was drawn onto a piece of paper with the ink facing upwards in view of the microscope's camera. The ROI profile shows hysteresis-like behaviour as the material changes from blue to colourless (heating) and back to blue (cooling). The onset of colour loss was measured at $44.2{ }^{\circ} \mathrm{C}$, also shown in micrographs A and B. Upon cooling, the colour return onset was observed in two steps with the main return measured at $-22.2{ }^{\circ} \mathrm{C}$, and micrographs $\mathrm{C}$ and $\mathrm{D}$ show this return in colour. The corresponding DSC profile showed no observable events, which was attributed to the low mass of ink and the orientation of the paper.

The benefit of this combined system means that very low energy transitions may still be detected using optical data even when the sample size is insufficient to be readily detected using DSC.

\section{Thermal transitions of a 3D printer filament}

$3 \mathrm{D}$ printing is well-established branch of additive manufacturing, and decreasing equipment costs have made the technique more accessible [22]. Currently, the most common type of 3D printer is based on fused deposition modelling (FDM). FDM works by melting a filament (typically polymeric) and extruding the molten material in the $X, Y$ and $Z$ directions to generate a 3D model [23].

It is of paramount importance to understand the properties of the filament, such as the glass transition, melting point and decomposition temperature, to ensure that optimal conditions are selected when extruding the filament to prevent damage to either the manufactured part and/or the printer [24].

Figure 7 shows the analysis of a sample of polylactic acid (PLA) 3D printer filament. The DSC profile shows a glass transition with an associated relaxation endotherm at an onset temperature of $59.9{ }^{\circ} \mathrm{C}$. The second event corresponds to the melting of the filament $\left(T_{\text {onset }} 145.1^{\circ} \mathrm{C}\right)$. These processes are shown more clearly in the expanded section of the
Fig. 7 The analysis of PLA 3D printer filament using the DSC450. The lower trace shows the DSC profile, and the upper shows the ROI profile both plotted as a function of temperature. The dashed DSC profile shows a scaled $(\mathrm{mW} \times 10)$ expansion of a key region. Selected micrographs (a-d) link to the ROI profile
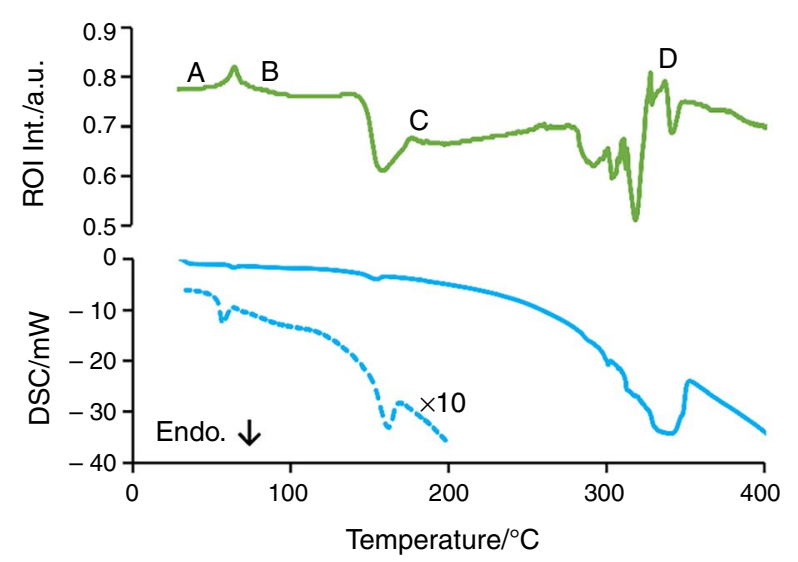

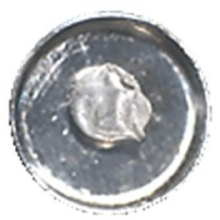

(a) $40^{\circ} \mathrm{C}$

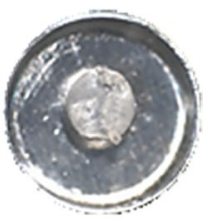

(b) $82{ }^{\circ} \mathrm{C}$

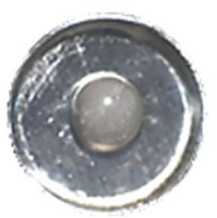

(c) $187^{\circ} \mathrm{C}$

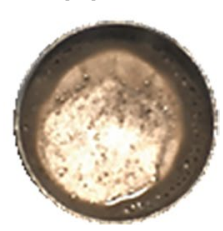

(d) $340^{\circ} \mathrm{C}$ 
DSC profile. The endotherm observed from 280 to $350{ }^{\circ} \mathrm{C}$ is attributed to polymer creep and then boiling, and the spikes observed in the baseline are consistent with gas bubbles bursting as they migrate through the molten polymer.

3D printer filaments often contain additives to enhance product durability or the aesthetics of the final extruded piece. These additives often inhibit the cold crystallisation observed for pure PLA and prevent the filament from becoming brittle prior to melting and extrusion [25]. As expected, no cold crystallisation exotherm was observed in this sample. As such, the broad and low energy melting event shown in the DSC profile indicates the low level of crystallinity in the sample.

The ROI profile corresponds closely to the DSC profile. An inflection shown in the ROI profile as the filament softens during the glass transition is observed in micrographs A to B. As the filament melts and coalesces into a sphere (micrograph C), a large step change is observed in the ROI profile. The ROI profile remains steady until the filament begins to boil when fluctuations are observed. These arise from the filament creeping to the outer edges of the pan, and the sharp spikes are consistent with bubbles bursting (micrograph D).

\section{Thermal degradation of magnesium nitrate hexahydrate}

Magnesium nitrate hexahydrate has been studied extensively as an energy storage material since it undergoes an aqueous fusion reaction, i.e. dissolves in its water of crystallisation, in the region of $90{ }^{\circ} \mathrm{C}$ [26]. Its thermal decomposition has also been of interest as a potential source of pure magnesium oxide [27]. Simultaneous DTA-mass spectrometry studies indicated that it was not possible to dehydrate the hexahydrate without some decomposition of the nitrate taking place a temperatures as low as $130^{\circ} \mathrm{C}$ [28]. Thermomicroscopy experiments indicated that the spikey nature of the DTA and evolved gas profiles was due to the vigorous evolution of the gaseous products from the aqueous melt [29].
Figure 8 shows results from the analysis of a sample of magnesium nitrate hexahydrate. The DSC profile shows a solid-solid phase transition $\left(T_{\text {onset }} 77.8^{\circ} \mathrm{C}\right)$, before leading into an aqueous fusion $\left(T_{\text {onset }} 90.9{ }^{\circ} \mathrm{C}\right)$. A slight exothermic baseline deviation is then observed at an onset of $200.2{ }^{\circ} \mathrm{C}$, which has been attributed to the formation of a 'skin' on the surface of the liquid. In the baseline between 220 and $280{ }^{\circ} \mathrm{C}$, spikes are observed and as in the previous $3 \mathrm{D}$ printer filament example have been attributed to bubbles bursting. An expanded region of the DSC trace has been included to show the noise generated by the endotherms of bubbles bursting.

After the bubbling has subsided, the solid partially decomposed anhydrous magnesium nitrate remains stable until a final melt is observed at $438^{\circ} \mathrm{C}$. These processes agree with those identified in earlier literature [29, 30].

The ROI profile follows the DSC closely showing most of the key events. The first major event noted is the step change as the sample undergoes its aqueous fusion. This transition may also be seen when comparing micrographs $\mathrm{A}$ and $\mathrm{B}$ as the magnesium nitrate crystals dissolve in their own waters of hydration. The next major feature observed is a peak about the temperature that the 'skin' forms, followed shortly after with a noisier baseline as the movement of bubbles is detected. Micrograph $\mathrm{C}$ has been included to show the skin that has formed over the melt, with vigorous bubbling underneath. The bubbling arises from the release of both water vapour and various $\mathrm{NO}_{\mathrm{x}}$ species, as confirmed by mass spectrometry studies performed by Madarasz et al. [30]. The final major process observed in the ROI profile is another step change as the solidified partially decomposed material melts indicated by the final endotherm in the DSC; this is also shown in micrograph $\mathrm{D}$ as the liquid pools to the edge of the analysis pan.
Fig. 8 The analysis of magnesium nitrate hexahydrate using the DSC450. The lower trace shows the DSC profile and the upper shows the ROI profile both plotted as a function of temperature. The inset shows an expansion of a key region. Selected micrographs (a-d) link to the DSC profile

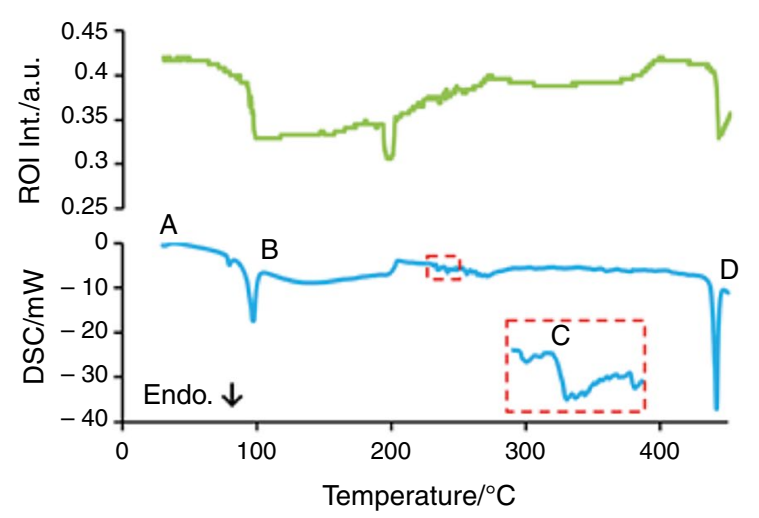

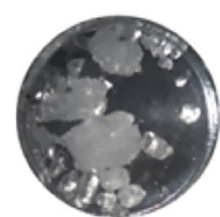

(a) $30^{\circ} \mathrm{C}$

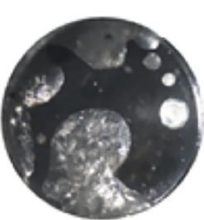

(c) $230^{\circ} \mathrm{C}$

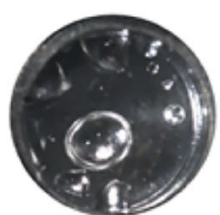

(b) $105^{\circ} \mathrm{C}$

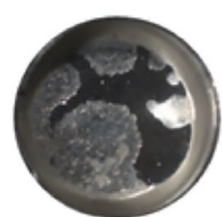

(d) $450^{\circ} \mathrm{C}$ 


\section{Conclusions}

Although many of the materials used in this study have been analysed using DSC and/or thermomicroscopy, experiments on them using a single instrument have not been previously reported.

- The oxidative induction time (OIT) test on a sample of polyethylene showed the expected DSC profile, but additional information on the subtle changes in surface morphology that occur at the onset of oxidation was revealed optically.

- The study of polymorphism in rubidium nitrate demonstrates how the use of reflected light intensity (RLI) can be beneficial even when the sample undergoes colourless transitions provided the sample undergoes changes in reflectivity or geometry.

- The solid-solid phase transition in a sample of silver iodide was observable both from the DSC profile and from the clear difference in colour of the two solid forms.

- The reversible changes in a small quantity of thermochromic ink on paper demonstrate the potential sensitivity of microscopy in thermal analysis. The changes in colour of the ink on heating and cooling were clearly apparent from both micrographs and RLI data even though the changes in enthalpy were too small to be observed with the DSC.

- The fluctuations observed in the DSC profile during the analysis of a sample of 3D printer filament were identified from the accompanying optical data as the effect of boiling, a process which otherwise would be difficult to assign with confidence.

- The thermal degradation of magnesium nitrate hexahydrate was found to give a complex DSC profile. However, by using both RLI and micrographs key transitions could be readily identified, such as the endotherms caused by bubbles bursting.

The results show the benefits of DSC-thermomicroscopy in the elucidation of complex thermal processes through the ability to obtain optical and enthalpic information simultaneously on a single sample.

Acknowledgements The authors would like to thank Linkam Scientific for the provision of the Optical DSC450 and the University of Huddersfield for funding.

Funding This research was funded by the University of Huddersfield.

Availability of data and materials Data files are available on request.

\section{Compliance with ethical standards}

Conflict of interest There are no conflicts of interest associated with this work.

Open Access This article is licensed under a Creative Commons Attribution 4.0 International License, which permits use, sharing, adaptation, distribution and reproduction in any medium or format, as long as you give appropriate credit to the original author(s) and the source, provide a link to the Creative Commons licence, and indicate if changes were made. The images or other third party material in this article are included in the article's Creative Commons licence, unless indicated otherwise in a credit line to the material. If material is not included in the article's Creative Commons licence and your intended use is not permitted by statutory regulation or exceeds the permitted use, you will need to obtain permission directly from the copyright holder. To view a copy of this licence, visit http://creativecommons.org/licenses/by/4.0/.

\section{References}

1. Charsley EL. Thermal analysis. In: Charsley EL, Warrington SB, editors. Techniques and applications. Cambridge: Royal Society of Chemistry; 1992. p. 59-83.

2. Haines P, Skinner GA. Simultaneous differential scanning calorimetry and reflected light intensity measurement. Thermochim Acta. 1982;59:343-59.

3. Hey JM, Mehl PM, MacFarlane DR. A combined differential scanning calorimeter-optical video microscope for crystallization studies. J Therm Anal. 1997;49:991-8.

4. Sauerbrunn S, Zemo M, Basilik T. DSC-thermomicroscopy. Am Lab. 2007;39:32-4.

5. Kunisha KS. An apparatus for thermoanalytical microscopy and its applications. Thermochim Acta. 1979;31:1-11.

6. Wiedemann HG. New TA system for simultaneous determination of thermo-optical properties and DSC of different organic compounds. J Thermal Anal. 1993;40:1031-40.

7. Dawson PC. Flow properties of molten polymers. In: Swallowe GM, editor. Mechanical properties and testing of polymers. Dordrecht: Kluwer; 1999. p. 88-95.

8. Qian S, Igarashi T, Nitta K-H. Thermal degradation behavior of polypropylene in the melt state: molecular weight distribution changes and chain scission mechanism. Polym Bull. 2011;67:1661-70.

9. Archodoulaki V-M, Luftl S, Seidler S. Oxidation induction time studies on the thermal degradation behaviour of polyoxymethylene. Polym Test. 2006;25:83-90.

10. Schmid M, Ritter A, Affolter S. Determination of oxidation induction time and temperature by DSC. J Therm Anal Calorim. 2006;83:367-71.

11. Borysiak S. The thermo-oxidative stability and flammability of wood/polypropylene composites. J Therm Anal Calorim. 2015;119:1955-62.

12. Charsley EL, Davies JP, Glöggler E, Hawkins N, Höhne GWH, Lever T, Peters K, Richardson MJ, Rothemund I, Stegmayer A. Sub-ambient and medium temperature certified DSC reference materials. J Therm Anal. 1993;40:1405.

13. Charsley EL, Laye PG, Markham HM, Hill JO. Determination of the equilibrium temperatures and enthalpies of the solid-solid transitions of rubidium nitrate by differential scanning calorimetry. Thermochim Acta. 2008;469:65-70. 
14. Funke K, Banhatti RD, Grabowski P, Nowinski J, Wrobel W, Dinnebier R, Magdysyuk O. Low-temperature $\alpha$-AgI confined in glass: structure and dynamics. Solid State Ion. 2015;271:2-9.

15. Hoshino H, Shimoji M. Electrical properties of silver iodide. J Phys Chem Solids. 1974;35:321-6.

16. Chadwick AV. Fast ion conductors. In: Yip S, editor. Handbook of materials modelling. Dordrecht: Springer; 2005. p. 1901-14.

17. Binner JGP, Dimitrakis G, Price DM, Reading M, Vaidhyanathan B. Hysteresis in the $\beta-\alpha$ transition in silver iodide. J Therm Anal Calorim. 2006;84:409-12.

18. Robb GR, Harrison A, Whittaker AG. Temperature-resolved, in situ powder X-ray diffraction of silver iodide under microwave irradiation. PhysChemComm. 2002;5:135-7.

19. JP Pat, JP4219776B2, 2003.

20. Khatami A, Prova SS, Bagga AK, Ting MYC, Brar G, Ifa DR. Detection and imaging of thermochromic ink compounds in erasable pens using desorption electrospray ionisation mass spectrometry. Rapid Commun Mass Spectrom. 2017;31:983-90.

21. Campbell DJ, Bosma WB, Bannon SJ, Gunter MM, Hammar MK. Demonstration of thermodynamics and kinetics using FriXion erasable pens. J Chem Educ. 2012;89:526-8.

22. Shahrubudin N, Lee TC, Ramlan R. An overview on 3D printing technology: technology, materials and applications. Proc Manuf. 2019;35:1286-96.

23. Cwikla G, Grabowik C, Kalinowski K, Paprocka I, Ociepka P. The influence of printing parameters on selected mechanical properties of FDM/FFF 3D-printed parts. IOP Conf Ser Mater Sci Eng. 2017;227:012033.

24. Coppola B, Cappetti N, Maio LD, Scarfato P, Incarnato L. 3D printing of PLA/clay nanocomposites: influence of printing temperature on printed sample properties. Materials. 2018;11:1947.

25. Ligon SC, Liska R, Stampfl J, Gurr M, Mulhaupt R. Polymers for $3 \mathrm{D}$ printing and customized additive manufacturing. Chem Rev. 2017;117:10212-90.

26. Honcova P, Pilar R, Danielik V, Soska P, Sadovska G, Honc D. Suppressing supercooling in magnesium nitrate hexahydrate and evaluating corrosion of aluminium alloy container for latent heat storage application. J Therm Anal Calorim. 2017;129:1573-81.

27. Gabdullin AN, Molodykh AS, Nikonenko EA, Nikitina EV, Tkacheva VE, Nevolina OA. High-temperature hydrolysis of magnesium nitrate hexahydrate. Russ Metall (Metally). 2017;8:627-30.

28. Aspinal ML, Madoc Jones HJ, Charsley EL, Redfern JP. A new instrument for simultaneous DTA-mass spectrometric analysis. In: Wiedemann HG, editor. Thermal analysis, vol. 1. Basel: Birkhauser Verlag; 1972. p. 303-12.

29. Charsley EL, Kamp ACF. A versatile hot stage microscope unit. In: Wiedemann HG, editor. Thermal analysis, vol. 1. Basel: Birkhauser Verlag; 1972. p. 499-513.

30. Madarasz J, Varga PP, Pokol G. Evolved gas analyses (TG/DTAMS and TG-FTIR) on dehydration and pyrolysis of magnesium nitrate hexahydrate in air and nitrogen. J Anal Appl Pyrolysis. 2007;79:475-8.

Publisher's Note Springer Nature remains neutral with regard to jurisdictional claims in published maps and institutional affiliations. 